\title{
Numerical and Experimental Investigation of the Thermal Comfort of an Office Building Equipped with Hybrid Downdraft Evaporative Cooler
}

\author{
1"HARUNA, IU; ${ }^{2}$ RUFAI, IA; ${ }^{2}$ YAHAYA, DB \\ ${ }^{* 1}$ Department of Mechanical Engineering, Federal Polytechnic Mubi, Adamawa State, Nigeria \\ Email: heldabuk@yahoo.com \\ ${ }^{2}$ Department of Mechanical Engineering, Bayero University Kano, Kano State, Nigeria \\ Email:iarufai.mec@buk.edu.ng \\ *Corresponding Author Email: heldabuk@yahoo.com
}

\begin{abstract}
In office buildings, provision of thermal comfort for occupant's high intellectual concentration, efficiency and productivity is imperative. This study experimentally and numerically investigates the thermal comfort performance of HDEC system equipped to an office building. The experiment was carried out in September, October and November for 24 working days and the thermal comfort Predicted Mean Vote (PMV) index being the objective function was determined using Centre for Built Environment thermal comfort tool. DesignBuilder CFD simulation software was employed to numerically determine the PMV index of the test office using ASHRAE Standard-55 thermal comfort range of $P M V= \pm 0.5$. Minitab 19 software was used to validate the numerical results against the experimental results. The Pearson correlation coefficient and the P-value at $95 \%$ confidence level were 0.717 and 0.00 respectively while the RMSE computed was 0.653 indicating a good agreement between the numerical and the experimental results. Both PMV results indicate that the HDEC system is suitable for the provision of thermal comfort in office buildings and any other similar building.
\end{abstract}

\section{DOI: https://dx.doi.org/10.4314/jasem.v25i8.14}

Copyright: Copyright (C) 2021 Haruna et al. This is an open access article distributed under the Creative Commons Attribution License (CCL), which permits unrestricted use, distribution, and reproduction in any medium, provided the original work is properly cited.

Dates: Received: 10 May 2021; Revised: 28 June 2021; Accepted: 01 July 2021

Keywords: Thermal comfort, Office building, Predicted Mean Vote, Hybrid downdraft evaporative cooler

The remarkable issues that frequently arise in building structures are energy consumption, thermal comfort and indoor air quality (Narguess and Arman, 2017; Haslinda et al., 2019). About $40 \%$ of the global energy is being consumed by the building sector and larger proportion of this energy is used for the provision of thermal comfort (Koranteng et al., 2015). Thermal comfort is defined as the condition of mind that expresses satisfaction with the thermal environment (Arandara et al., 2010; ANSI/ASHRAE Standard-55, 2017). An office building is a space where organized official activities are carried out. These official activities can only be performed when office occupants are thermally comfortable. Therefore, the productivity, efficiency and intellectual concentration of office occupants to a very large extent hinge on the thermal comfort (De Vecchi et al., 2017; Kabrein et al., 2017). Thermal comfort in buildings can be achieved through various means such as the use of refrigeration-based air conditioning systems, natural or forced ventilation systems, evaporative coolers, and passive systems such as shading devices, thermal mass, nocturnal thermal radiation, removable canvass etc. (Calautit et al., 2020). The refrigeration-based air conditioning systems, apart from consuming high energy, are characterized by poor indoor air quality because of the recirculation of air with partial fresh air replacement and also contribute significantly to global warming (Kang and Strand, 2013). The office occupants more often than not rely on ventilation (natural or forced) system to achieve thermal comfort by opening their windows. When the ambient wind speed is still or low, natural ventilation cannot effectively cool the space likewise when forced ventilation is used, during the hot season when cooling is needed most, the heat that emanates from the fan motor and the heat generated due friction between the fan blades and the air molecules add to the cooling load of the office building (Cengel, 2002). Evaporative coolers cool an occupied space adiabatically by sensible and latent heat exchange between the incoming air and the water vapour (Kulkarni and Rajput, 2010). Inside occupied buildings, different performance criteria have been developed for the evaluation of thermal comfort. Among others are the Adaptive Thermal Comfort (ATC), Predicted Mean Vote (PMV), Predicted Percentage of Dissatisfied (PPD), Standard Effective Temperature (SET), and Corrected Effective Temperature (CET) (Haslinda et al, 2019; ASHRAE Standard-55, 2010). With the 
exception of PMV and PPD, most of the other methods have limitations since they are dependent on specific climatic conditions (Haslinda et al., 2019). Hence, the PMV and the PPD are widely employed in assessing the thermal comfort scenarios of occupied buildings. The PMV is an index that is used to predict the mean value of the votes of a large of persons on the seven point scale of thermal sensation which ranges from -3 to +3 (ASHRAE Standard-55, 2010). The PPD is an index that represents the percentage of persons that are thermally dissatisfied with the condition of the occupied space (Prakash and Ravikumar, 2015; Barbara et al., 2014; Toby et al., 2019).

There are several methods used to examine the thermal comfort scenario of occupied buildings. Some of these techniques are analytical models, empirical models, small-scale experimental models, full-scale experimental models, and computational fluid dynamics (CFD) (Chen, 2009). Although the full-scale experimental model is relatively expensive, it and CFD give better and reliable results. Experimental and CFD approaches have been used in many studies for the investigation of indoor thermal comfort in occupied buildings (Tao et al., 2011; Hussain, 2012; Rajagopalan and Luther, 2013).

The objective of this article is to numerically and experimentally investigate the thermal comfort of an office building equipped with hybrid downdraft evaporative cooler (HDEC) using predictive mean vote (PMV) as the control performance criterion.

\section{MATERIALS AND METHODS}

Description of the study are: The characteristics of the study area are presented in Table 1.

\begin{tabular}{ll}
\multicolumn{2}{c}{ Table 1: Characteristics of the Case Study } \\
\hline Title & Characteristics \\
\hline Building type & Office \\
Location & Bayero University, Kano, Nigeria \\
& Latitude: $12.05^{\circ} \mathrm{N}$ \\
& Longitude: $8.53^{\circ} \mathrm{E}$ \\
& Elevation: $481 \mathrm{~m}$ above sea level \\
Number of floors & 1 \\
Floor height & $3.0 \mathrm{~m}$ \\
Occupancy (person $\left./ \mathrm{m}^{2}\right)$ & 0068 \\
Orientation & North - South \\
Number of windows & 2 located on adjacent walls \\
Dimension of office & $4.0 \mathrm{~m}$ long, $3.7 \mathrm{~m}$ wide and $3.0 \mathrm{~m}$ \\
& high \\
\hline
\end{tabular}

Experimental Investigation of the Indoor Thermal Comfort: The fabricated HDEC system was shown in Figure 1(a) while the installed HDEC system to the site office building at the Centre of Excellence of Bayero University Kano was shown in Figure 1(b).
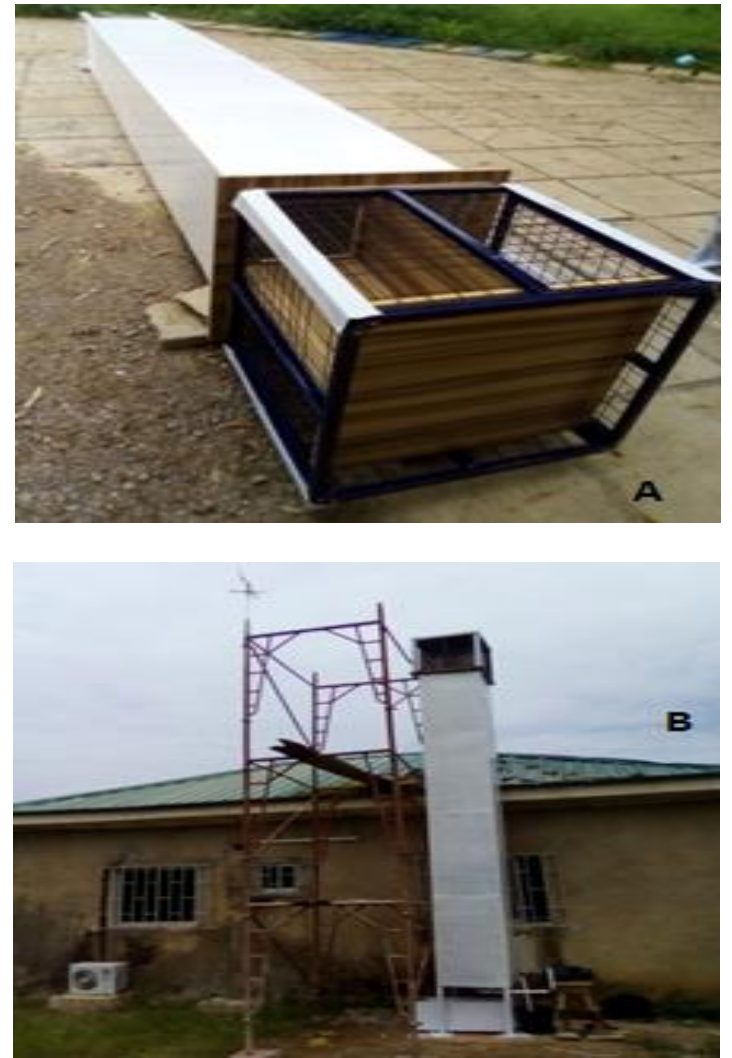

Fig 1: HDEC and its Integration to the Office Building: (A) HDEC System (B) Integrated HDEC-Office Building
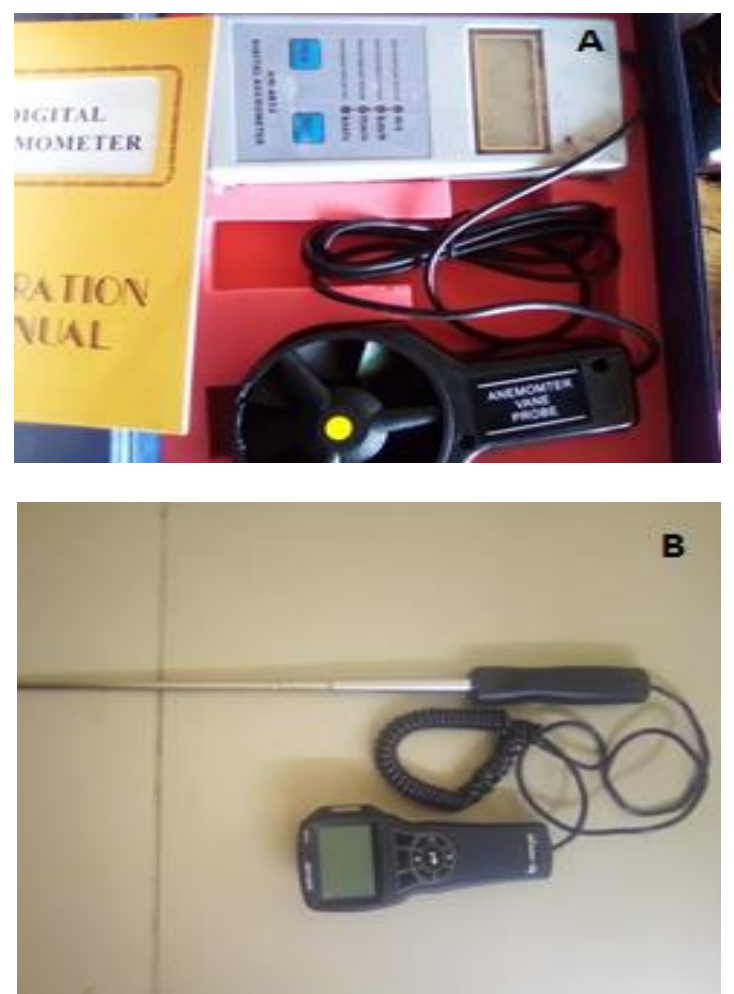

Fig 2: Digital Vane Anemometers and Probe Airflow Meter: (A) Digital vane anemometer (B) Digital probe airflow meter 
The experiment was conducted for the period of three months from $30^{\text {th }}$ September to $15^{\text {th }}$ November 2020. The readings were taken on hourly basis from 9:00am to 4:00pm from Monday to Friday which represent the normal official working period. The outdoor and indoor dry bulb and wet bulb temperatures were measured using hygrometers while the indoor air velocity, HDEC exit air temperature and velocity as well as the windcatcher inlet velocity were measured using digital probe airflow meter shown in Figure 2(b). The outdoor wind speed was measured at a point adjacent to the windcatcher at the height of $6 \mathrm{~m}$ above the ground level using digital vane anemometer shown in Figure 2(a).

The indoor condition of the test office was measured at the centre of the room at the height of $1.1 \mathrm{~m}$ above the flow level as shown in Figure 3. This height represents the shoulder of a seated person as recommended by ASHRAE Standard-55, 2010.

Daily averages of the indoor experimental data: indoor temperature $\left(T_{i}\right)$, indoor air velocity $\left(V_{i}\right)$, and indoor relative humidity $\left(R H_{i}\right)$ were presented in Table 2 . For clothed person sitting and doing light work typical for an academic office, an assumed metabolic rate $(M)$ of 1.0 met and a clothing insulation of 0.5 clo were used while the mean radiant temperature $\left(T_{m r}\right)$ was taken to be equal to the indoor dry bulb temperature $\left(T_{r}\right)$ as recommended by ASHRAE Standard-55, 2010. These six environmental and personal thermal comfort parameters were uploaded into the CBE thermal comfort tool shown in Figure 4 which is in compliance with ASHRAE Standard-55 2013.

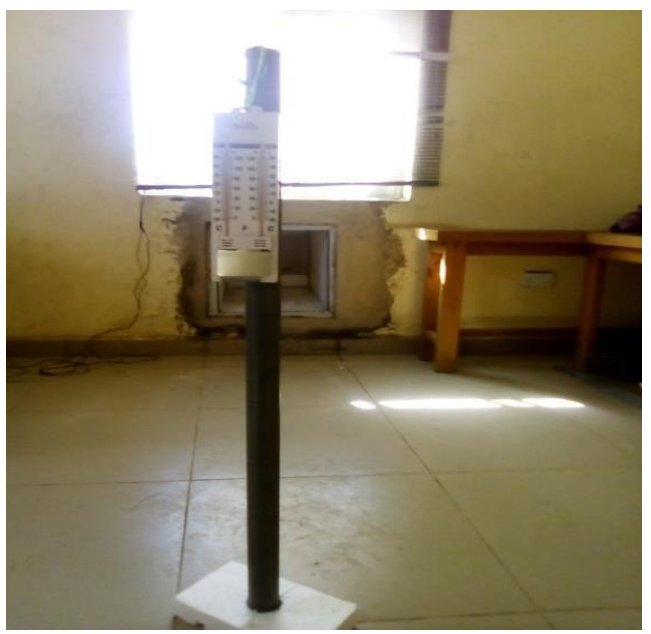

Fig 3 Indoor Condition Measured at 1.1m Height

Table 2: PMV of Average Indoor Experimental Data

\begin{tabular}{llllllll}
\multicolumn{7}{c}{ Tabperimental 2: PMV of Average Indoor Experimental Data } \\
\hline Day & $\begin{array}{l}T_{i} \\
\left({ }^{\circ} \mathrm{C}\right)\end{array}$ & $\begin{array}{l}V_{i} \\
(\mathrm{~m} / \mathrm{s})\end{array}$ & $\begin{array}{l}R H_{i} \\
(\%)\end{array}$ & $\begin{array}{l}T_{m r} \\
\left({ }^{\circ} \mathrm{C}\right)\end{array}$ & $\begin{array}{l}M \\
(\text { met })\end{array}$ & $\begin{array}{l}I \\
(\text { clo })\end{array}$ & $P M V_{e}$ \\
\hline 1 & 27.51 & 0.024 & 77.13 & 27.51 & 1.00 & 0.50 & 0.87 \\
2 & 28.36 & 0.055 & 84.88 & 28.36 & 1.00 & 0.50 & 1.29 \\
3 & 28.16 & 0.024 & 86.63 & 28.16 & 1.00 & 0.50 & 1.23 \\
4 & 29.81 & 0.040 & 84.88 & 29.81 & 1.00 & 0.50 & 1.88 \\
5 & 31.01 & 0.060 & 80.50 & 31.01 & 1.00 & 0.50 & 2.30 \\
6 & 28.08 & 0.036 & 83.88 & 28.08 & 1.00 & 0.50 & 1.17 \\
7 & 26.21 & 0.046 & 82.25 & 26.21 & 1.00 & 0.50 & 0.40 \\
8 & 27.28 & 0.048 & 84.38 & 27.28 & 1.00 & 0.50 & 0.85 \\
9 & 27.98 & 0.051 & 76.00 & 28.00 & 1.00 & 0.50 & 1.05 \\
10 & 28.65 & 0.063 & 76.63 & 28.65 & 1.00 & 0.50 & 1.32 \\
11 & 29.08 & 0.030 & 78.25 & 29.08 & 1.00 & 0.50 & 1.51 \\
12 & 25.65 & 0.044 & 78.85 & 25.65 & 1.00 & 0.50 & 0.14 \\
13 & 24.78 & 0.023 & 78.38 & 24.68 & 1.00 & 0.50 & -0.25 \\
14 & 24.01 & 0.026 & 77.00 & 24.01 & 1.00 & 0.50 & -0.53 \\
15 & 24.70 & 0.016 & 79.13 & 24.70 & 1.00 & 0.50 & -0.23 \\
16 & 25.36 & 0.014 & 76.50 & 25.36 & 1.00 & 0.50 & 0.01 \\
17 & 24.96 & 0.083 & 74.63 & 24.96 & 1.00 & 0.50 & -0.17 \\
18 & 25.28 & 0.020 & 74.25 & 25.15 & 1.00 & 0.50 & -0.09 \\
19 & 24.76 & 0.031 & 74.25 & 24.71 & 1.00 & 0.50 & -0.27 \\
20 & 24.65 & 0.035 & 75.12 & 24.65 & 1.00 & 0.50 & -0.29 \\
21 & 24.11 & 0.044 & 77.50 & 24.01 & 1.00 & 0.50 & -0.52 \\
22 & 23.51 & 0.040 & 77.50 & 23.99 & 1.00 & 0.50 & -0.73 \\
23 & 23.67 & 0.048 & 76.13 & 23.67 & 1.00 & 0.50 & -0.95 \\
24 & 24.14 & 0.051 & 73.88 & 24.02 & 1.00 & 0.50 & -0.80 \\
\hline
\end{tabular}

The Predicted Mean Vote $\left(P M V_{e}\right)$ of the test room was then computed using the Centre for Built Environment (CBE) thermal comfort tool (Federico et al., 2020). The computed $P M V_{e}$ for the experimental days were shown on the time series plot in Figure 5.
Numerical Investigation of the Indoor Thermal Comfort: In the base case simulation, both external and internal CFD analyses were performed on the 3D building model in Figure 6 while keeping the windowto-wall ratio (WWR) constant. 
The HDEC exit air condition largely determines the thermal condition of the test room. Therefore, the experimental HDEC exit air temperature and flowrate alongside the six PMV parameters were used as part of the boundary conditions for the base case simulation using the DesignBuilder CFD software. The air velocities through the window opening during the simulation runs were determined using external CFD analysis. The CFD computational domain and one of the external CFD simulations carried out are shown in Figure 7. The velocities through the window opening were used to compute the air flow rate in (litres/second) which was used for the internal CFD analysis.

Pinchrometic chat (an temperatire)

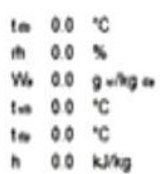

in $00 \mathrm{kmg}$

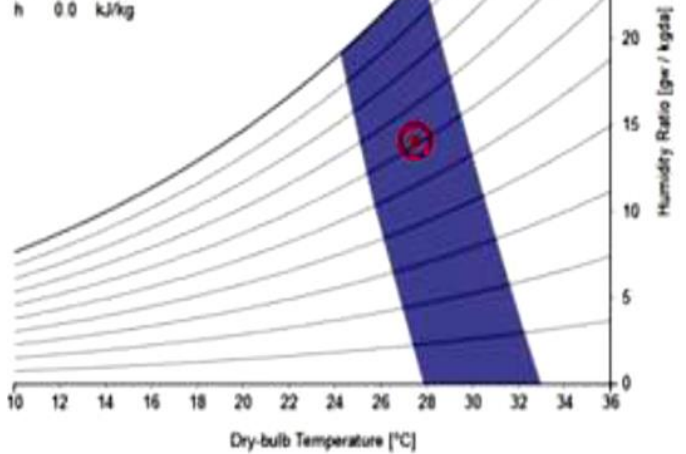

Fig 4. CBE Thermal Comfort Tool

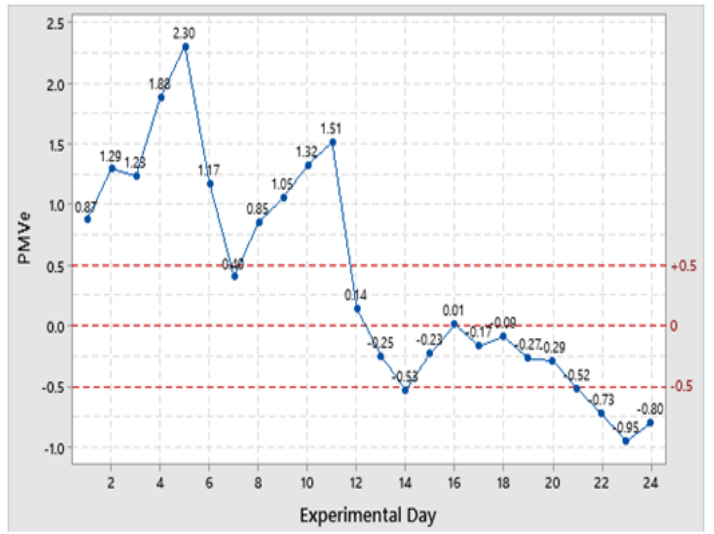

Fig 5 Average Daily Time Series Plot of $P M V_{e}$ Results

The simulated $P M V_{S}$ results were obtained using the internal CFD analysis. The 3D contour plots of the internal CFD analysis for the numerical determination of the thermal comfort $P M V_{s}$ for the first simulation run is shown in Figure 8 and the results for the whole 24 simulation runs are shown on the time series plot in Figure 9.

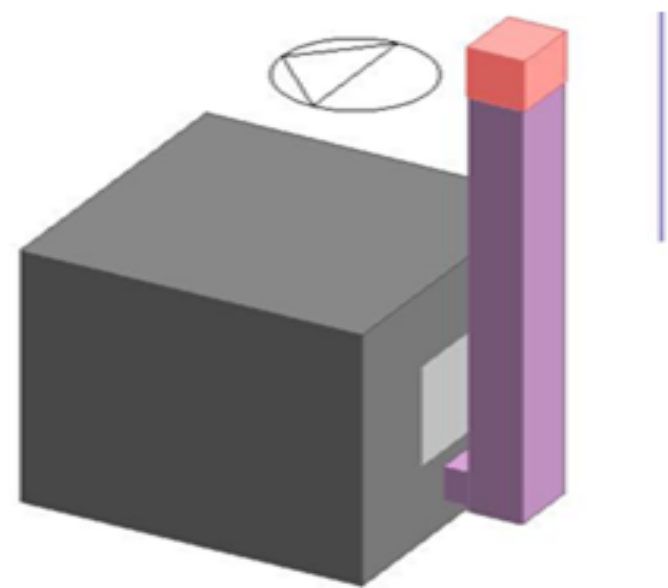

Fig 6. 3D Integrated HDEC-Office Building Model

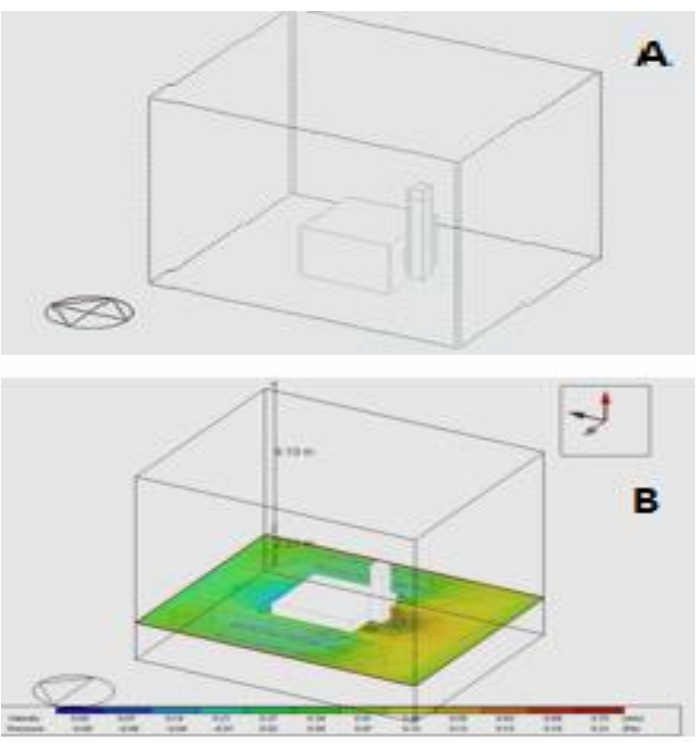

Fig 7. External CFD Simulation of Integrated HDEC-Office Building (A) CFD Computational Domain (B) CFD Simulation of the Building Model

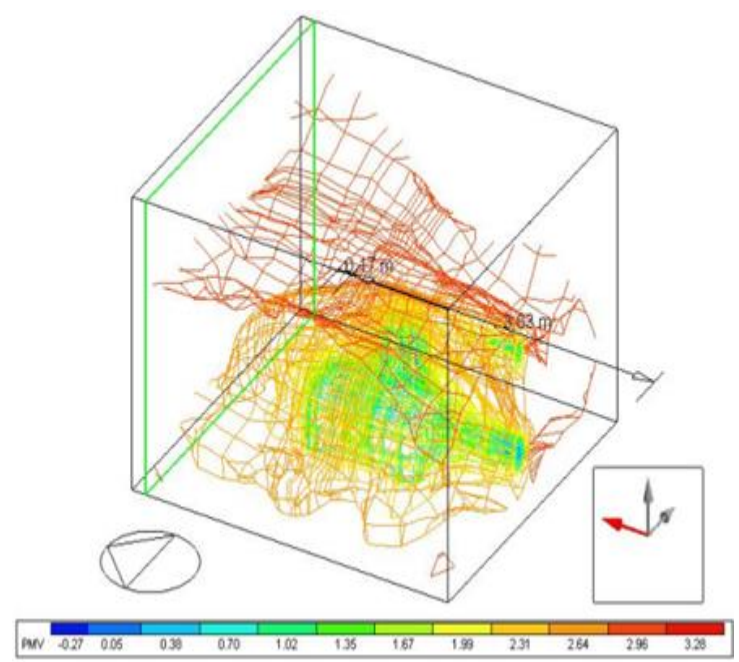

Fig 8 3D Contour Plots of $\mathrm{PMV}_{\mathrm{s}}$ CFD Simulation Run 1 


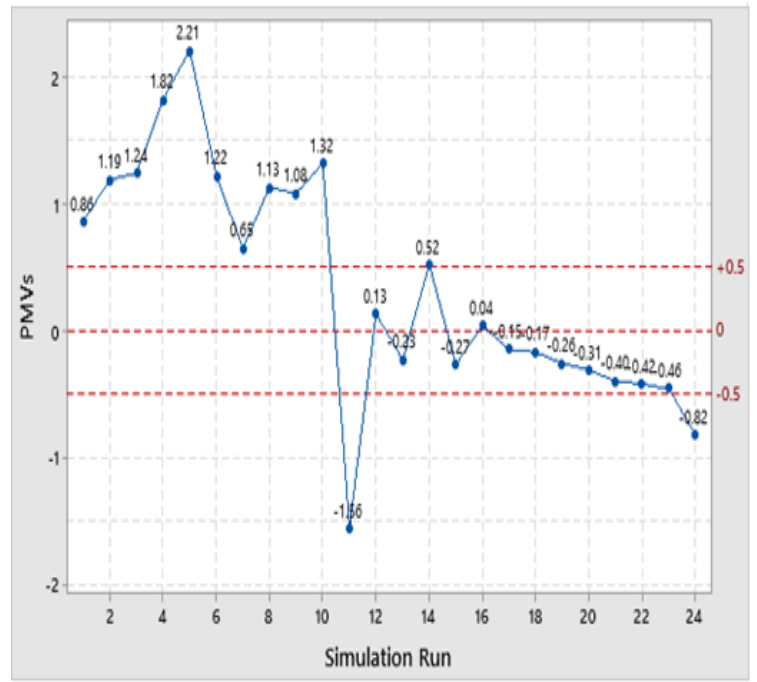

Fig 9. Times Series Plot of $P M V_{s}$ Results for the 24 Simulation Runs

Validation of the Numerical Results: The simulated $P M V_{s}$ values were validated against the experimental $P M V_{e}$ values using the statistical software package Minitab 19. The results of this validation were presented in Table 3 and the line of best fit is shown in Figure 10.

Table 3: Pairwise Pearson Correlations for PMV Validation

\begin{tabular}{|c|c|c|c|}
\hline \multicolumn{2}{|r|}{ Sample } & Correlation & P-value \\
\hline 1 & Simulated $P M V_{S}$ & & \\
\hline 2 & Experimental $P M V_{e}$ & 0.717 & 0.000 \\
\hline
\end{tabular}

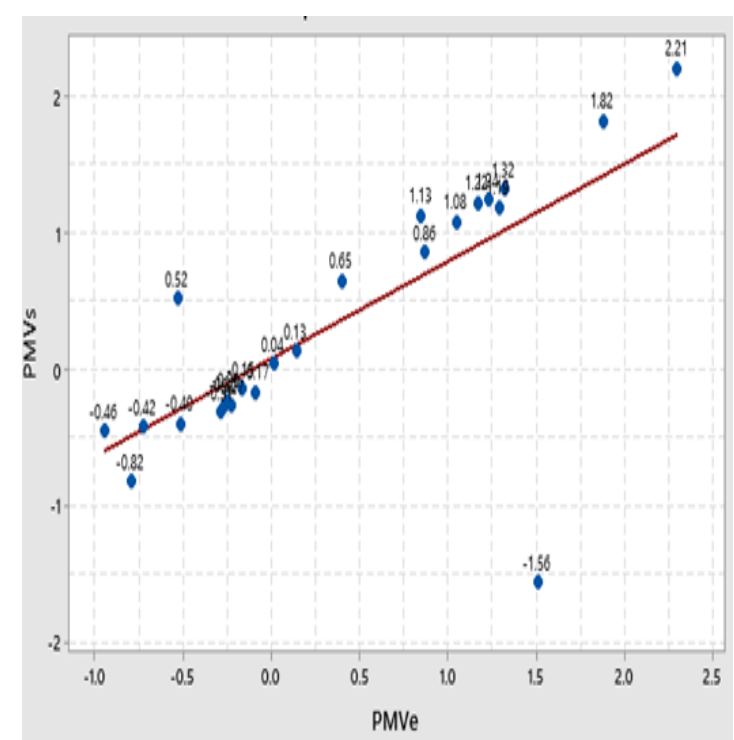

Fig 10 Agreement Between Simulated and Experimental PMV Results

\section{RESULTS AND DISCUSSION}

Figures 5 and 9 show that the $P M V_{e}$ and $P M V_{s}$ values that fall within the ASHRAE recommended range for thermal comfort on the scale of thermal sensation range from -0.29 to +0.40 and -0.46 to +0.13 respectively. These represent about $33.3 \%$ and $45.8 \%$ respectively of the experimental days when thermal comfort was achieved based on the recommended ASHRAE Standard-55 thermal comfort range from $-0.5<P M V<+0.5$. Most of the experimental days that fall outside the recommended comfort range in this case had relatively higher relative humidity and temperature. Temperatures and relative humidity outside the recommended thermal comfort range recorded during the experiment contributed significantly to the $P M V_{e}$ values falling outside the recommended thermal comfort range. This agreed with ASHRAE Standard-55 (2010) and the reported work of Zhibin et al. (2019) and Franceska et al. (2013) who stated that in a natural ventilation setting, air temperature ranges from $23^{\circ} \mathrm{C}$ to $27^{\circ} \mathrm{C}$ and relative humidity ranges from $30 \%$ to $70 \%$ for thermal comfort. It is worthwhile to note that HDEC system is a direct evaporative cooling system that cools the incoming outdoor air adiabatically. Hence, the higher the wet bulb temperature, the higher the relative humidity and therefore the less the cooling effect. Furthermore, the high humidity level inside the test room could partly be explained by the way the WWR was kept constant throughout the experiment. In order to mitigate moisture accumulation and at the same time provide thermal comfort for the occupant of a space equipped with the HDEC system, using optimum window geometry is imperative. From Table 3 , the $\mathrm{P}$-value of the validation of the simulated results against the experimental results was 0.00 while the coefficient of correlation was 0.717 . This means that there is a significant correlation between the two results at $95 \%$ confidence level. The RMSE was computed to be 0.693 thereby confirming the agreement between the simulated and the experimental results.

Conclusion: The thermal comfort of occupants in an office building equipped with the HDEC system was evaluated through numerical CFD simulation and field testing. Field test data was employed to validate the numerical modelling, showing good agreement between the two methods. The investigation showed that the HDEC system can improve the thermal comfort of occupants in an office building or any other building with similar architectural settings.

\section{REFERENCES}

ANSI/ASHRAE Standard 55-2017: Thermal Environmental Conditions for Human Occupancy, Vol. 66, ASHRAE Inc., 2017

Arandara, KP; Attalage, RA; Jayasingh, MTR (2010). Thermal Comfort with Evaporative Cooling for 
Tropical Climates. Int. Conf. on Sust. Built Environ. (ICSBE-2010) Kandy, 13-14 December.

ASHRAE Standard 55 (2010), Thermal Environmental Condition for Human Occupancy, American Society of Heating, Refrigeration and Air-Conditioning Engineers, Atlanta, GA.

ASHRAE Standard 55 (2013), Thermal Environmental Condition for Human Occupancy, American Society of Heating, Refrigeration and Air-Conditioning Engineers, Atlanta, GA.

ASHRAE Standard 55 (2017), Thermal Environmental Condition for Human Occupancy, American Society of Heating, Refrigeration and Air-Conditioning Engineers, Atlanta, GA.

Barbara, S; Christian, K; Emmanuel, A; Joshua, A (2014). An Assessment of Thermal Comfort in Multi Storey Office Buildings in Ghana. J. of Build.Constr. and Plan. Res. 2: $30-38$.

Calautit, JK; O'Conno, D; Sofotasiou, P; Hughes, BR (2015). CFD Simulation and Optimization of a Low Energy Ventilation and Cooling System, Comp. 3(2): 128-149.

Cengel, YA (2002). Heat Transfer - Practical Approach. Tata McGraw-Hill, West Patel Nagar, New Delhi.

Chen, Q (2009). Ventilation Performance Prediction for Buildings: A Method Overview and Recent Applications, Build. and Environ. 44(4): 848-858

De Vecchi, R; Candido, C; de Dear, R; Lamberts, R (2017). Thermal comfort in Office Buildings: Findings from a Field Study in Mixed -Mode and Fully-Air Conditioning Environments Under Humid Subtropical Conditions. Build. and Ener. DOI: 10.1016/j.buildenv.2017.07.029

Federico, T; Stefano, S; Toby, C; Tyler, H (2020). CBS Thermal Comfort Tool: Online tool for thermal comfort calculations and visualizations. SoftwareX https://doi.org/10.1016/j.softx.2020.100563

Francesca, RAA; Elvira, L; Boris, IP (2013). PMV - PPD and Acceptability in Naturally Ventilated Schools. Build. and Environ. 67: 129 - 137.

Haslinda, MK; Kamsah, NB; Ghaleb, FA; Alhamid, MI (2019). Enhancement of Thermal Comfort in a Large Space Building. Alex. Eng. J. 58: $49-65$.

Hussain, S (2012). Numerical Investigations of the Indoor Thermal Environment in Atria and of the Buoyancydriven Ventilation in a Simple Atrium Building (Doctoral Dissertation), Queen's University (Canada).

Kabrein, H; Yusof, MZM; Hariri, A; Leman, A; Afandi, A (2017). Improving Indoor Air Quality and Thermal Comfort in Office Building by using Combination
Filters. Mat. Sci. and Eng. doi:10.1088/1757899X/243/1/012052

Kang, D (2011). Advances in the Application of Passive Downdraft Evaporative Cooling Technology in the Cooling of Buildings. $\mathrm{PhD}$ Thesis in Architecture, University of Illinois.

Kang, D; Strand, RK (2013). Modelling of Simultaneous Heat and Mass Transfer within Passive Downdraft Evaporative Cooling (PDEC) Tower with Spray in FLUENT. Ene and Build. 63: 196 - 209.

Koranteng, C; Essel, C; Nkrumah, J (2015). Passive Analysis of the Effect of Window Size and Position on Indoor Comfort for Residential Rooms in Kumasi, Ghana. Int. Adv. Res. J. in Sci., Eng and Technol. 2(10): $114-120$.

Kulkarni, RK; Rajput, SPS (2010).Theoretical Performance of Analysis of Jute Fibre Rope Bank as Media in Evaporative Coolers. Indian J. of Sci. and Technol. 3(10): $1075-1080$

Narguess, K; Arman, H (2107). Improving Thermal Comfort and Indoor Air Quality through Minimal Interventions in Office Buildings. 8th Int. Conf. on Sust. in Ene. and Build. SEB-16, 11-13 September, Turin, Italy.

Prakash, D; Ravikumar, P (2013). Study of Thermal Comfort in a Room with Window at Adjacent Walls along with Additional Vents. Indian J. of Sci. and Tech. 6(6).

Rajagopalan, P; Luther, MB (2013). Thermal and Ventilation Performance of a Naturally Ventilated Sports Hall within an Aquatic Centre. Ene. and Build. 58: $111-122$

Tao, HG; Chen, HX; Xie, JL; Jiang, JZ (2011). Comparison on Simulation and Experiment of Supply Air through Metro Vehicle Air Conditioning Duct, in: Appl. Mech. and Mat. 1724-1728.

Toby, C; Stefano, S; Thomas, P; Peixian, L; Gail, B (2019). Analysis of the Accuracy of PMV-PPD Model using the ASHRAE Global Thermal Comfort Database II. Build. and Environ https://doi.org/10.1016/j.buildenv.2019.01.055

World Meteorological Organization (WMO), Daily Climate Weather Data, 2011 www.geodata.us/weather/place.php?Usaf $=650460 \ldots \mathrm{C}$ =Nigeria

Zhibin, W; Nianping, L; Pawel, W; Jingqing, P; Jingming, L (2019). Adaptive Thermal Comfort in Naturally Ventilated Dormitory Buildings in Changsha, China Energy. Build. 1 (186): $56-70$ 